\title{
A Prospective Cohort Study on Sustained Effects of Low-Dose Ecstasy Use on the Brain in New Ecstasy Users
}

\author{
Maartje ML de Win*,',2, Liesbeth Reneman', Gerry Jager', Erik-Jan P Vlieger', Sílvia D Olabarriaga ${ }^{4}$, \\ Cristina Lavini', Ivo Bisschops', Charles BLM Majoie', Jan Booij ${ }^{5}$, Gerard J den Heeten' and \\ Wim van den Brink ${ }^{6}$
}

'Department of Radiology, Academic Medical Center, University of Amsterdam, Amsterdam, The Netherlands; ${ }^{2}$ Graduate School Neurosciences, Amsterdam, The Netherlands; ${ }^{3}$ Department of Psychiatry, Rudolf Magnus Institute of Neuroscience, University Medical Center, Utrecht, The Netherlands; ${ }^{4}$ Informatics Institute, University of Amsterdam, Amsterdam, The Netherlands; ${ }^{5}$ Department of Nuclear Medicine, Academic Medical Center, University of Amsterdam, Amsterdam, The Netherlands; ${ }^{6}$ Amsterdam Institute for Addiction Research and Department of Psychiatry, Academic Medical Center, University of Amsterdam, Amsterdam, The Netherlands

It is debated whether ecstasy use has neurotoxic effects on the human brain and what the effects are of a low dose of ecstasy use. We prospectively studied sustained effects ( $>2$ weeks abstinence) of a low dose of ecstasy on the brain in ecstasy-naive volunteers using a combination of advanced MR techniques and self-report questionnaires on psychopathology as part of the NeXT (Netherlands XTC Toxicity) study. Outcomes of proton magnetic resonance spectroscopy ( $\left.{ }^{\mathrm{H}} \mathrm{H}-\mathrm{MRS}\right)$, diffusion tensor imaging (DTI), perfusion-weighted imaging (PWI), and questionnaires on depression, impulsivity, and sensation seeking were compared in 30 subjects (I2M, $21.8 \pm 3.1$ years) in two sessions before and after first ecstasy use (1.8 \pm 1.3 tablets). Interval between baseline and follow-up was on average 8.I \pm 6.5 months and time between last ecstasy use and follow-up was $7.7 \pm 4.4$ weeks. Using 'H-MRS, no significant changes were observed in metabolite concentrations of $\mathrm{N}$-acetylaspartate (NAA), choline (Cho), myo-inositol ( $\mathrm{ml}$ ), and creatine ( $\mathrm{Cr}$ ), nor in ratios of $\mathrm{NAA}$, Cho, and $\mathrm{ml}$ relative to $\mathrm{Cr}$. However, ecstasy use was followed by a sustained $0.9 \%$ increase in fractional anisotropy (FA) in frontoparietal white matter, a 3.4\% decrease in apparent diffusion (ADC) in the thalamus and a sustained decrease in relative regional cerebral blood volume (rrCBV) in the thalamus (-6.2\%), dorsolateral frontal cortex (-4.0\%), and superior parietal cortex ( $-3.0 \%)$ (all significant at $p<0.05$, paired $t$-tests). After correction for multiple comparisons, only the rrCBV decrease in the dorsolateral frontal cortex remained significant. We also observed increased impulsivity ( $+3.7 \%$ on the Barratt Impulsiveness Scale) and decreased depression (-28.0\% on the Beck Depression Inventory) in novel ecstasy users, although effect sizes were limited and clinical relevance questionable. As no indications were found for structural neuronal damage with the currently used techniques, our data do not support the concern that incidental ecstasy use leads to extensive axonal damage. However, sustained decreases in rrCBV and ADC values may indicate that even low ecstasy doses can induce prolonged vasoconstriction in some brain areas, although it is not known whether this effect is permanent. Additional studies are needed to replicate these findings.

Neuropsychopharmacology (2007) 32, 458-470. doi:I 0. I038/sj.npp. I 30 I225; published online I November 2006

Keywords: MDMA; neurotoxicity; brain imaging; DTI; PWI; 'H-MR Spectroscopy

\section{INTRODUCTION}

There is increasing evidence that ecstasy (3,4-methylenedioxymethamphetamine, MDMA) is toxic to the human brain, especially to the serotonergic system (eg, McCann

\footnotetext{
*Correspondence: Dr MML de Win, Department of Radiology, Academic Medical Center, University of Amsterdam, GI-229, Meibergdreef 9, II05 AZ Amsterdam, The Netherlands, Tel: + 31 20 5669 III, tracer 81 58963, Fax: +31 20 5669119,

E-mail: m.m.dewin@amc.uva.nl

Received 21 February 2006; revised 21 August 2006; accepted 28 August 2006

Online publication: 14 September 2006 at http://www.acnp.org/ citations/Npp09|406060 | | 8/default.pdf
}

et al, 2000; Reneman et al, 2006), although the validity of these findings is still highly debated (Turner and Parrott, 2000; Grob, 2002; Kish, 2002). Many human studies are littered with methodological problems, including inadequate sampling of subjects and controls, lack of drug use analysis, and lack of baseline data (eg, Morgan, 2000; De Win et al, 2005). The latter argument leads to interpretative difficulties concerning causality between ecstasy use and potential toxicity, because it leaves open the possibility that differences between ecstasy users and controls were preexistent, as discussed previously by others (Jansen and Forrest, 1999; Morgan, 1999; Dughiero et al, 2001). It may be possible that personality traits like impulsivity and sensation seeking, associated with substance misuse, are 
related to lower serotonergic function (Khantzian, 1997; Zuckerman and Kuhlman, 2000) or that results are biased by confounding variables such as polydrug use, gender, and lifestyle.

Few prospective studies were performed in which MDMA was administered to volunteers either with (Downing, 1986; Grob et al, 1996; Camí et al, 2000; Chang et al, 2000) or without prior experience with ecstasy use (Greer and Tolbert, 1986; Vollenweider et al, 1998; Gamma et al, 2000; Liechti et al, 2000; Liechti and Vollenweider, 2000a, b). Most of these studies focused on acute and not on sustained or permanent effects of ecstasy. These studies have led to ongoing discussion on safety and ethics of administration of potentially neurotoxic drugs to healthy humans. Several authors objected to administering a potential neurotoxic drug to humans for the purpose of science (Gijsman et al, 1999; McCann and Ricaurte, 2001), while others supported these experiments (Lieberman and Aghajanian, 1999; Vollenweider et al, 1999, 2001).

The discussion mainly persists, because it is assumed that heavy ecstasy use most probably causes adverse long-term effects (eg, McCann et al, 1998; Reneman et al, 2001a), while it is not known whether a low dose of ecstasy can cause lasting brain damage. Effects of a single dose of ecstasy in ecstasy-naive humans were only described up to $24 \mathrm{~h}$ after intake (Vollenweider et al, 1998), while persisting psychopathology after a single dose was only described in case reports (McGuire et al, 1994; Vaiva et al, 2001). In rats, neuronal damage was demonstrated in various brain areas following a single dose of MDMA (Colado et al, 1995; Schmued, 2003), including persistent effects on behavior (Ho et al, 2004). In addition, studies in primates showed serotonin depletion 2 weeks after administering a single $(5 \mathrm{mg} / \mathrm{kg}$ ) (Ricaurte et al, 1988) or two oral doses $(4.3 \mathrm{mg} /$ $\mathrm{kg}$ ) (Mechan et al, 2006). The validity of animal data for the human situation has been questioned, however, because MDMA is usually administered to animals in higher dosages than generally used by humans. Some authors do not support the suggestion that a single oral dose at $1.7 \mathrm{mg} / \mathrm{kg}$ is likely to produce neurotoxic effects in humans (Lieberman and Aghajanian, 1999; Vollenweider et al, 1999, 2001). On the other hand, it has been advocated that these dosages in animals are equivalent to typical recreational dosages in humans according to the principles of interspecies scaling (Ricaurte et al, 2000; McCann and Ricaurte, 2001).

It is important to know whether a low dose of ecstasy is neurotoxic for at least two reasons. First, recreational use of ecstasy is common among adolescents and young adults and many of them are 'experimenters' who take ecstasy incidentally and will not become heavy or regular users (The Netherlands National Drug Monitor, 2004). Determining that the incidental use of ecstasy could cause persisting neuronal damage would have major clinical and social implications. Second, it is debated whether MDMA should become available for medical use, because MDMA may be useful as an adjunct in psychotherapy, or whether this would lead to neuronal damage (Check, 2004). This discussion is of interest, since pilots have been approved that will study therapeutic effects of MDMA on anxiety in patients with post-traumatic stress disorder (Check, 2004) and in terminally ill cancer patients (Bender, 2005). When considering ecstasy as adjunct in psychotherapy, it is important that estimations of risk are available to decide whether potential risks outweigh potential benefits.

With advanced magnetic resonance (MR) techniques, such as proton magnetic resonance spectroscopy $\left({ }^{1} \mathrm{H}-\mathrm{MRS}\right)$, diffusion tensor imaging (DTI), and perfusion weighted imaging (PWI) it is possible to study various aspects of neuronal damage in the brain.

${ }^{1} \mathrm{H}$-MRS allows to study certain metabolites in the brain, such as $\mathrm{N}$-acetylaspartate (NAA), choline-containing compounds (Cho), myo-inositol ( $\mathrm{mI}$ ), and (phospho)creatine (Cr). NAA is decreased in neuronal damage and impaired cognition (Ross et al, 1997). Cho is increased in brain diseases that involve increased membrane breakdown, myelination, or inflammation, and it is thought to reflect cellular density (Miller et al, 1996). MI is a putative glial cell marker increased in diseases that involve gliosis (Ross et al, 1997). Cr is often used as an internal reference (Pouwels and Frahm, 1998). Previous studies in heavy ecstasy users showed decreased NAA/Cr in the prefrontal cortex (Reneman et al, 2002), correlated to decreased memory function (Reneman et al, 2001c) and increased $\mathrm{mI} / \mathrm{Cr}$ in the parietal white matter (Chang et al, 1999). However, another study could not confirm lower NAA/Cr ratios in cortical brain regions, and observed only a tendency towards lower $\mathrm{NAA} / \mathrm{Cr}$ ratios in the left hippocampus of ecstasy users (Daumann et al, 2004a).

With DTI it is possible to measure diffusional motion of water molecules. In the brain, the motion is restricted in amplitude and direction by cellular structures such as axons. (Sub)acute processes that involve axonal injury and ischemia can lead to a decreased apparent diffusion coefficient (ADC) of water due to cytotoxic edema (Haykin et al, 2005). However, in chronic stage of axonal damage, ADC can be increased and fractional anisotropy (FA) of water can be decreased due to increased extracellular water content. It is difficult to determine the time course of change in ADC. For stroke, transition from decreasing to increasing ADC values seems to occur between $18 \mathrm{~h}$ and 7 days after stroke onset (Copen et al, 2001), while delayed cytotoxic edema with restricted ADCs was described up to 6 months, after carbon monoxide poisoning (Murata et al, 2001; Chu et al, 2004), and heroin abuse (Chen et al, 2000). Only one article was published with ADC measurements in heavy ecstasy users, and showed increased ADC values in the globus pallidus (Reneman et al, 2001b).

Finally, PWI can map regional relative cerebral blood volume ( $\mathrm{rCBV}$ ) using the dynamic susceptibility contrast (DSC) technique (Belliveau et al, 1990; Levin et al, 1996). This is of interest because serotonin is involved in regulation of brain microcirculation (Cohen et al, 1996). Previous publications described cerebrovascular accidents, such as cerebral infarction and hemorrhage, (Hanyu et al, 1995; Lee et al, 2003) and cerebrovascular changes (Chang et al, 2000; Reneman et al, 2000, 2001b) in ecstasy users. It is expected that ecstasy use induces a (sub)acute increase of extracellular serotonin leading to vasoconstriction, whereas the long-term effect of ecstasy use may be a decrease in extracellular serotonin and thus vasodilatation.

If a low dose of ecstasy is neurotoxic, it is important to know whether this has clinical consequences in terms of psychopathological parameters such as mood, impulsivity, and sensation seeking. Many previous studies reported 
increased levels of depression (Sumnall and Cole, 2005), impulsivity (Morgan, 1998; Parrott et al, 2000; Tuchtenhagen et al, 2000; Daumann et al, 2001, 2004b; Bond et al, 2004; Butler and Montgomery, 2004), and sensation/novelty seeking (Gerra et al, 1998; Tuchtenhagen et al, 2000; Schifano, 2000; Dughiero et al, 2001) in ecstasy users, although it is unclear whether these associations reflect a causal relationship, that is whether ecstasy use causes changes in mood, impulsivity, and sensation seeking or whether depression, impulsivity, and sensation seeking increase the probability of (heavy) ecstasy use (see also De Win et al, 2006).

The aim of the present study was to assess whether a low dose of ecstasy would be neurotoxic. Using a prospective naturalistic study design, parameters of neurotoxicity measured with ${ }^{1} \mathrm{H}$-MRS, DTI, and PWI and outcomes of psychopathological self-report inventories on depression, impulsivity, and sensation seeking were compared between a baseline session before first ecstasy use and a follow-up session after ecstasy use. Based on previous findings, we hypothesized that if a low dose of ecstasy has sustained effects on the brain MR-derived parameters and psychopathology would show relatively small changes between both sessions, that is a decrease (in the subacute stage shortly after ecstasy use) or increase (after a longer period of abstinence) in rrCBV and ADC, depending on the time since last ecstasy use; an increase in Cho (or Cho/Cr), $\mathrm{mI}$ (or $\mathrm{mI} / \mathrm{Cr}$ ), depression, impulsivity, and sensation seeking; and a decrease in FA and NAA (or NAA/Cr).

\section{MATERIALS AND METHODS}

\section{Participants}

The current study is part of the NeXT (Netherlands XTC Toxicity) study, which investigates causality, course, and clinical relevance of ecstasy neurotoxicity. A detailed description of the NeXT study and recruitment strategies can be found in a special design paper (De Win et al, 2005). Between April 2002 and April 2004, 188 young adults (77 M, $111 \mathrm{~F}$, age $21.7 \pm 3.0$ years) were included in the study. They had never used ecstasy, but were selected on a relatively high probability to start using ecstasy in the near future. Subjects were recruited using a combination of targeted site sampling, advertisement through a website on the project, and snowball sampling referrals. Main inclusion criteria were intention to probably or certainly use ecstasy for the first time in near future and/or having friends who already used ecstasy. Exclusion criteria were: ecstasy use in the past (at baseline), age below 18 or above 35 years, severe physical or mental illness, use of psychotropic medications such as serotonin reuptake inhibitors, pregnancy, use of intravenous drugs, and contraindications for MRI (eg, claustrophobia, pacemaker). Subjects had to abstain from psychoactive substances for at least 2 weeks and from alcohol for at least 1 week before examinations. This was checked by urine drug screening (enzyme-multiplied immunoassay for amphetamines, ecstasy, opiates, cocaine, benzodiazepine, cannabis, and alcohol).

The study was approved by the local medical ethics committee. Subjects were informed about potential negative consequences of ecstasy use and all subjects signed informed consent. Subjects received an allowance for their participation (between $€ 100$ and $€ 150$ per session).

\section{Study Procedure and Measurements of Confounders}

At baseline all 188 subjects underwent MR imaging, including ${ }^{1} \mathrm{H}-\mathrm{MRS}$, DTI, and PWI, and completed selfreport questionnaires on depression, impulsivity, and sensation seeking. After baseline examination, subjects had to complete questionnaires (four in total) about their drug use at regular intervals over a period of approximately 18 months. For the present study, the first 31 incident ecstasy users were included in a first follow-up session, relatively soon after their first ecstasy use (after we received their first drug use questionnaire indicating use of ecstasy) and with a maximum cumulative ecstasy dose of 10 tablets. During the follow-up session, ${ }^{1} \mathrm{H}-\mathrm{MRS}$, DTI, PWI, and self-report questionnaires on depression, impulsivity, and sensation seeking were repeated.

At both sessions, subjects had to complete questionnaires about potential confounders, such as demographic variables and education. Various aspects of lifetime ecstasy use (frequency of use, cumulative dose, and duration of use), and last year use of alcohol (units per week), tobacco (cigarettes per week), cannabis (number of joints last year), amphetamines (number of times used last year), and cocaine (number of times used last year) were assessed using substance-use questionnaires (Van de Wijngaart et al, 1997). Verbal intelligence was estimated using The Dutch Adult Reading Test (DART), the Dutch version of the National Adult Reading Test (Nelson, 1991).

\section{Image Acquisition}

MR imaging was performed on a $1.5 \mathrm{~T}$ scanner (Signa Horizon, LX 9.0, General Electric Medical Systems, Milwaukee, WI, USA) using the standard head coil. The protocol included (1) an axial PD- and T2-weigthed sequence (echo time $(\mathrm{TE})_{1} / \mathrm{TE}_{2} /$ relaxation time $(\mathrm{TR})=10 / 98 / 4000 \mathrm{~ms}, 12$ slices of $5 \mathrm{~mm}, 1.5 \mathrm{~mm}$ slice distance, $23 \mathrm{~cm}$ field of view (FOV)); (2) three ${ }^{1} \mathrm{H}-\mathrm{MRS}$ scans with the single voxel point-resolved spectroscopy (PRESS) sequence $(\mathrm{TE} / \mathrm{TR}=$ 35/1500 ms); (3) DTI: diffusion-weighted spin echo Echo Planar Imaging (EPI) $(\mathrm{TE} / \mathrm{TR}=90 / 8000 \mathrm{~ms}, 12$ slices of $5 \mathrm{~mm}$, $1.5 \mathrm{~mm}$ slice distance, $23 \mathrm{~cm} \mathrm{FOV;} b=0$ and $1000 \mathrm{~s} / \mathrm{mm}^{2}$, $128 \times 128$ matrix); (4) PWI: gradient echo EPI first-pass dynamic $\mathrm{T}_{2}^{*}$-weighted contrast-enhanced imaging (TE/ $\mathrm{TR}=55 / 2000 \mathrm{~ms}$, 12 slices of $5,1.5 \mathrm{~mm}$ slice distance, $23 \mathrm{~cm}$ FOV); and (5) a high resolution T1-weigthed 3D scan using a Fast Spoiled GRadient Echo (FSPGR) sequence (TE/ $\mathrm{TR}=6 / 30 \mathrm{~ms}$, voxel size $\left.1.0 \times 1.0 \times 1.4 \mathrm{~mm}^{3}\right)$. Throughout the study positioning of subjects in the scanner and positioning of the slices and voxels were performed by the same examiner and according to a protocol to keep positioning as reproducible as possible.

The voxel size for ${ }^{1} \mathrm{H}$-MRS was $6.5 \mathrm{ml}\left(18 \times 18 \times 20 \mathrm{~mm}^{3}\right)$ and voxels were placed in the left centrum semiovale (frontoparietal white matter) and in mid-frontal and midoccipital gray matter as in previous publications (Chang et al, 2000; Reneman et al, 2002). Shimming and water suppression were automatically performed by the scanner. Diffusion was measured in six non-collinear directions 
and in the six opposite directions. For each of these 12 directions $\left(b=1000 \mathrm{~s} / \mathrm{mm}^{2}\right)$ and for a baseline measurement without diffusion weighting $\left(b=0 \mathrm{~s} / \mathrm{mm}^{2}\right)$, two acquisitions were averaged. Perfusion images were obtained at 2 -s intervals for $80 \mathrm{~s}$. At $6 \mathrm{~s}$ after the start of image acquisition, a bolus $(0.12 \mathrm{ml} / \mathrm{kg})$ with gadobutrol $1.0 \mathrm{~mol} / \mathrm{l}$ (Gadovist 1.0; Schering, Berlin, Germany) was injected, using a power-injector (Spectris MR injector; Medrad, Indianpolis, PA, USA) at a rate of $5 \mathrm{ml} / \mathrm{s}$ through a cannula inserted in the antecubital vein. The gadobutrol injection was followed by a $15-\mathrm{ml}$ saline flush $(0.9 \% \mathrm{NaCl})$.

\section{Image Analysis}

Spectra derived from ${ }^{1} \mathrm{H}$-MRS were analyzed using LCModel (Linear Combination of Model spectra) (Provencher, 1993). This is a user-independent analysis method that estimates absolute metabolite concentrations by fitting the in vivo spectra to a set of previously acquired in vitro spectra (the basis set). This procedure allows the absolute quantification of metabolite concentrations. Both absolute concentrations of NAA, Cho, $\mathrm{mI}$, and $\mathrm{Cr}$ as well as the ratios of NAA to $\mathrm{Cr}$, Cho to $\mathrm{Cr}$, and $\mathrm{mI}$ to $\mathrm{Cr}$ were calculated with LCModel. Quality control of ${ }^{1} \mathrm{H}$-MRS included checking of line-width and the percent SD of the estimated concentrations after analyses by LCModel. Unsuppressed spectra with a waterpeak line-width of more than $6 \mathrm{~Hz}$ were excluded. Also $\% \mathrm{SD}>20 \%$ for NAA and $\% \mathrm{SD}>50 \%$ for Cho, $\mathrm{mI}$, and $\mathrm{Cr}$ were considered unreliable and were excluded (Srinivasan et al, 2004).

The DTI scans were corrected for the effects of residual eddy currents by matching the images acquired with opposite diffusion sensitizing gradients to each other with an affine transformation, and then correcting both images with the 'half of that transformation (Bodammer et al, 2004). From the resulting diffusion weighted images, ADC, and FA maps were calculated as described elsewhere (Hunsche et al, 2001). The AMC Postprocessing Package (APP, http://amcpostpack.sourceforge.net) was used to calculate CBV maps from the PWI scans.

All image-derived parameters (FA, ADC, and CBV) were spatially normalized by registration to the Montreal Neurological Institute brain template (MNI152) in three steps. First, the scans corresponding to baseline measurements in the DTI and PWI sequences were individually matched to the T2-weighted images by 2D-non-rigid registration (program align_warp, Automated Image Registration Library, AIR, Woods et al, 1998). Second, the T2 scans were rigidly registered to the T1-3D scans (program flirt, fMRIB Software Library, FSL, Smith et al, 2004). Finally, the T1-3D scans were registered to the MNI152 brain template by a non-rigid transformation (align_warp). The transformations calculated to align the baseline measurements into $\mathrm{T} 2, \mathrm{~T} 2$ into $\mathrm{T} 1-3 \mathrm{D}$, and $\mathrm{T} 1-3 \mathrm{D}$ into MNI152 were applied to align the FA, ADC, and CBV maps to the MNI152 brain (see Figure 1 for representative images of individual FA, ADC, and CBV images after transformation to the MNI152 brain template). All images were skullstripped (program bet, FSL, Smith, 2002). Segmentation of white and gray matter was performed using T1-3D and PD scans (program fast, FSL, Gudbjartsson and Patz, 1995). The scans were segmented into three classes of tissue (CSF,
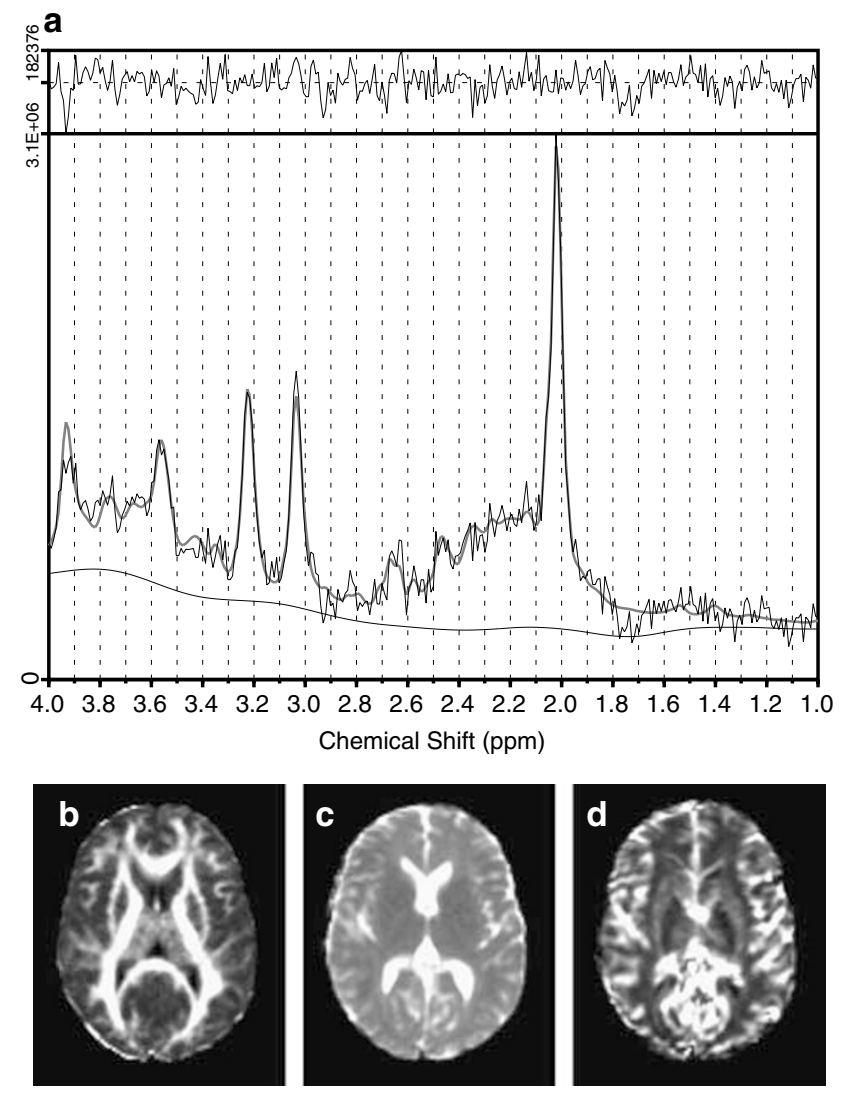

Figure I Representative images of an individual (a) 'H-MR spectrum after analysis by LCModel and representative (b) FA, (c) ADC, and (d) CBV images after transformation to the spatially normalized MNI brain template.

white, and gray matter), and the tissues of interest were isolated into separated binary maps (only white matter, only gray matter, and combined white and gray matter). The $\mathrm{CBV}$ maps were intensity-scaled to mean individual CBV intensity of white matter derived from the segmentation procedure to generate relative $\mathrm{CBV}$ ( $\mathrm{rCBV}$ ) maps.

Regions of interest (ROIs) were drawn on the MNI152 brain template in the thalamus, putamen, globus pallidus, head of the caudate nucleus, centrum semiovale (frontoparietal white matter), and dorsolateral frontal, mid-frontal, occipital, superior parietal, and temporal cortex (see Figure 2). For the cortical ROIs, only voxels within the gray matter mask were included and for the ROIs of the basal ganglia only voxels within the combined white and gray matter mask were included (CSF voxels were excluded). Selection of ROIs was based on findings of previous studies, which indicated that ecstasy-induced abnormalities are most prominent in basal ganglia and cortical areas; ecstasy-induced abnormalities in white matter were rarely reported and thus not expected. As cortical gray matter has very low anisotropy, it is very difficult to get reliable FA and ADC measurements in cortical areas. For this reason only white matter and basal ganglia ROIs were taken into account in the measurements of FA and ADC. Within the ROIs, individual mean values of $\mathrm{FA}, \mathrm{ADC}$, and regional relative $\mathrm{CBV}$ ( $\mathrm{rCBV}$ ) were calculated. Values of FA, ADC, and rrCBV from ROIs in left and right hemispheres were averaged. 


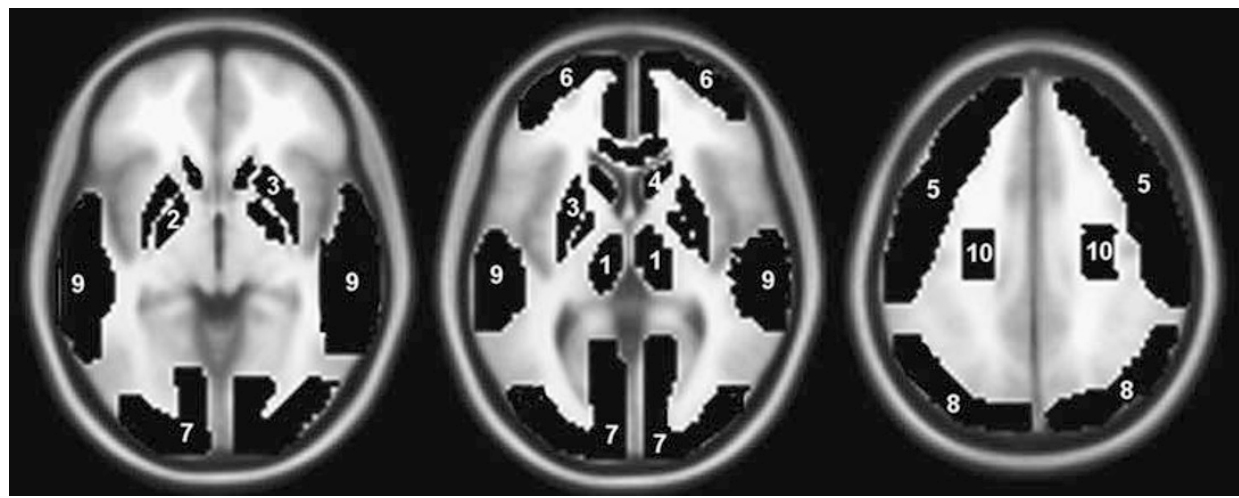

Figure 2 Region of interests used for analyses of DTI (measuring FA and ADC) and PWI (measuring rrCBV) drawn on the MRI brain template at three levels: (I) thalamus, (2) globus pallidus, (3) putamen, (4) caudate nucleus, (5) dorsolateral frontal cortex, (6) mid-frontal cortex, (7) occipital cortex, (8) superior parietal cortex, (9) temporal cortex, and (10) white matter of the centrum semiovale. Note that rrCBV was measured in all these ROIs and FA and ADC only in the white matter and basal ganglia ROls.

For each individual scan, all steps in the post-processing and analysis were visually inspected to check the quality of image registration and segmentation.

\section{Psychopathological Assessments}

Current depressive symptoms were assessed using the Beck Depression Inventory (BDI) (Beck et al, 1961), a 21-item self-report inventory that measures characteristic attitudes and symptoms of depression in the week before assessment. Impulsivity was assessed using the Dutch version of the Barratt Impulsiveness Scale (BIS-11), a reliable measure of impulsiveness (Patton et al, 1995). The Dutch BIS-11 contains 31 self-reported items. The Spannings Behoefte Lijst (SBL), a Dutch adaptation of the Sensation Seeking Scale (Zuckerman and Link, 1968) with 51 items, was used to measure sensation seeking as it has proven to be a reliable measure for research populations (Feij et al, 1982; Feij and van Zuilen, 1984).

\section{Statistical Analyses}

All substance-use variables were log-transformed because they were not normally distributed. First, paired $t$-tests, uncorrected for multiple comparisons, were used to assess whether parameters of substance use, imaging, and selfreport questionnaires had changed between baseline session before ecstasy use and follow-up session after ecstasy use.

Second, paired $t$-tests were repeated for imaging and psychopathology parameters excluding volunteers with increased cocaine use between both sessions $(N=4$, leaving $N=26$ for the second analysis), because paired analysis of substance use showed an increased frequency of cocaine use between baseline and follow-up sessions.

Third, previous studies showed that effects of ecstasy might be dose-dependent (McCann et al, 1998; Reneman et al, 2001a) and that females are more vulnerable for the effects of ecstasy than males (Reneman et al, 2001a; Buchert et al, 2004). Other studies suggested a relationship between brain perfusion and time since last ecstasy use and between $\mathrm{ADC}$ and time since onset of neuronal damage (Chang et al, 2000; Reneman et al, 2000). Therefore, we performed separate multiple linear regression analyses with follow-up measures of imaging and self-reported psychopathology as dependent variable and gender, cumulative dose of ecstasy, period of abstinence (weeks since last ecstasy tablet) and change in cocaine use (because this was the only significantly increased drug-use parameter) as independent variable and baseline measures of imaging and self-reported psychopathology as covariates.

Finally, Pearson correlations were calculated between statistically significant changes in MR outcomes and significant changes in outcomes of the psychopathology questionnaires.

The chance of a type I error $(\alpha)$ was set at 0.05 for all analyses. In addition, Bonferroni post hoc corrections were performed for the analyses of the imaging parameters, adjusting the $\alpha$-level for multiple comparisons. The adjusted $\alpha$-level was set at 0.006 for ${ }^{1} \mathrm{H}$-MRS outcomes (nine comparisons), at 0.010 for $\mathrm{FA}$ and $\mathrm{ADC}$ (five comparisons each), and at 0.005 for rrCBV (10 comparisons).

All statistical analyses were performed using SPSS version 11.5; SPSS Inc., Chicago, IL, USA). Mean values reported in the result section are followed by their standard deviations (mean $\pm \mathrm{SD}$ ). In the tables mean differences between the paired measurements are reported with their 95\% confidence intervals (95\% CI) and in the text the percentage difference and the two-tailed significance level ( $p$-values) are reported.

\section{RESULTS}

\section{Characteristics of the Sample and Substance Use}

Of the 188 ecstasy-naive subjects at baseline, 31 subjects were included in the first follow-up session relatively soon after their first ecstasy use (12 M, $19 \mathrm{~F}$, age $21.7 \pm 3.1$ years). One female was excluded because of a positive urine test on cocaine, leaving 30 volunteers for analysis with a mean age of 21.8 years. Characteristics of the sample and their substance use are described in Table 1. The interval between the baseline and follow-up sessions was on average $8.1 \pm 6.5$ months (range: 0.9-29.5 months). At this first follow-up session incident ecstasy users had used a mean of $1.8 \pm 1.3$ ecstasy tablets (range: 0.5-6; median 1.4 tablets). The majority had used ecstasy only once $(N=18 ; 60 \%)$. Six 
Table I Characteristics of Demographics, Use of Ecstasy and Other Substances, and Psychopathological Assessments ( $N=30)$

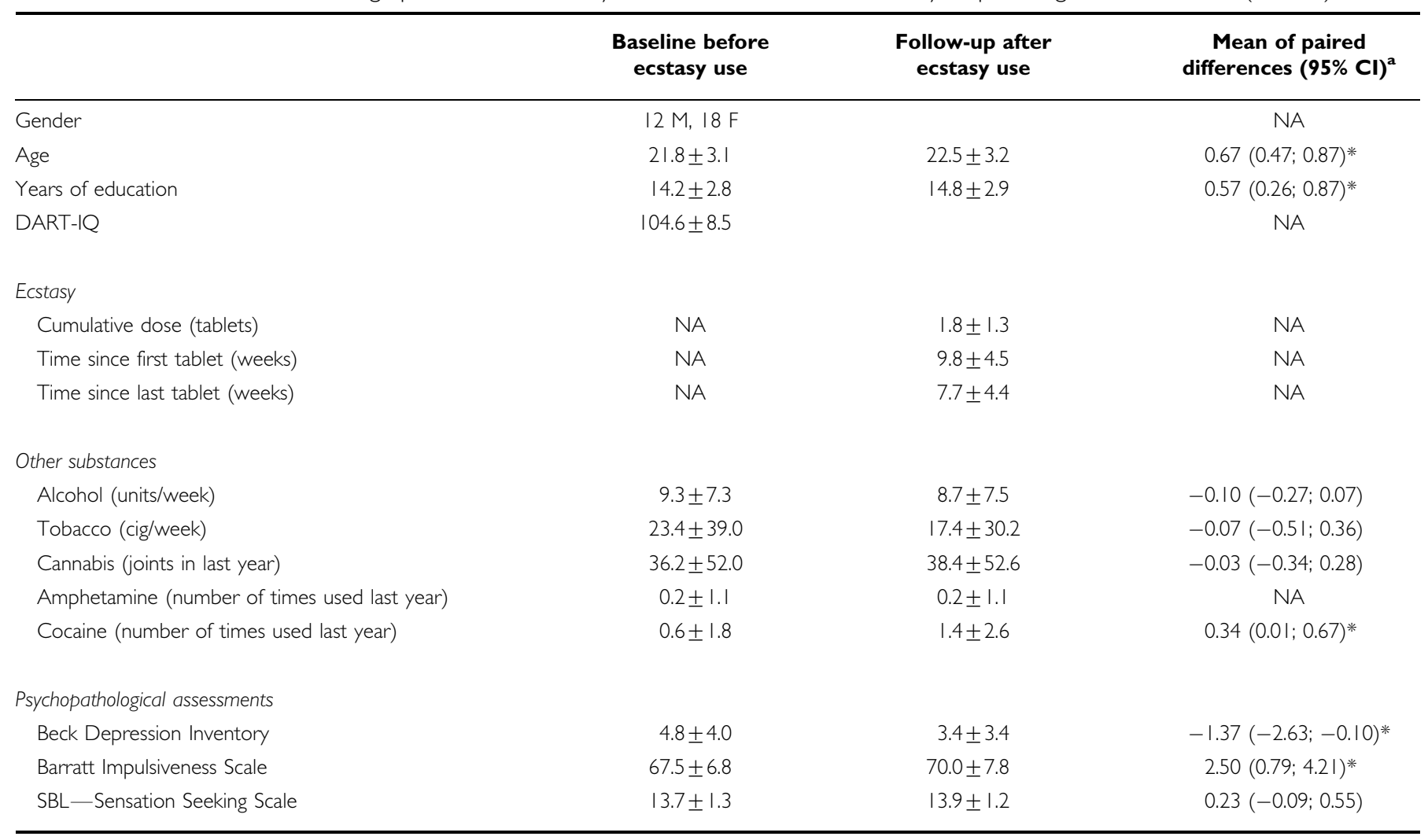

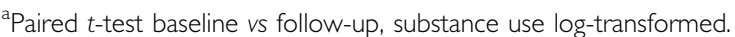

* Statistical significant difference between base line and follow-up.

Values expressed as mean \pm SD's. Results expressed in mean of paired differences $(95 \% \mathrm{Cl})$.

subjects $(20 \%)$ had used more than one ecstasy tablet at the same occasion with a maximum of two tablets per occasion. The interval between the last ecstasy use and follow-up measurements was $7.7 \pm 4.4$ weeks.

Table 1 shows that besides the use of ecstasy, there was a significant increase in cocaine use between sessions $(p=0.043)$, while there was no change in use of other substances.

\section{${ }^{1} \mathrm{H}-\mathrm{MRS}, \mathrm{DTI}$, and PWI}

The maximum line-width of the unsuppressed spectra was $6 \mathrm{~Hz}$ and maximum \%SD of the estimated metabolite concentrations was $20 \%$ for NAA and Cho and $25 \%$ for $\mathrm{mI}$, and therefore, all spectra could be included. However, due to technical problems with the scanner it was not possible to perform ${ }^{1} \mathrm{H}$-MRS in two subjects at the follow-up session.

Anatomical images (T1 3D scans and T2-weighted scans) were read by a neuroradiologist for atrophy or white matter lesions, and no significant abnormalities were detected. However, one subject had enlarged lateral ventricles and visual inspection showed this hampered matching to the standard brain, and therefore the measurements of FA, $\mathrm{ADC}$, and rrCBV of this subject were not included. Therefore, we report comparisons between baseline and follow-up measurements of FA, ADC, and $\mathrm{rrCBV}$ in 29 subjects and of ${ }^{1} \mathrm{H}$-MRS in 28 subjects.
Table 2 shows results of all measurements and Figure 3 illustrates the statistically significant findings. There were no significant changes in absolute concentrations of NAA, $\mathrm{Cho}, \mathrm{mI}$, and $\mathrm{Cr}$ and in ratios of $\mathrm{NAA}, \mathrm{Cho}$, or $\mathrm{mI}$ relative to $\mathrm{Cr}$ in any of the three voxels after ecstasy use. With DTI, we observed a small but significant increase of $0.9 \%$ in FA of the white matter of the centrum semiovale $(p=0.027)$ and a significant decrease of $3.4 \%$ in ADC of the thalamus $(p=0.015)$ after ecstasy use. With PWI we found significant decreases in $\mathrm{rrCBV}$ in the thalamus $(-6.2 \%, p=0.010)$, dorsolateral frontal gray matter $(-4.0 \%, p=0.001)$, and superior parietal gray matter $(-3.0 \%, p=0.029)$ (Figure 3$)$. When adjusted for multiple comparisons using the Bonferroni correction, only the decreased rrCBV value in the dorsolateral frontal gray matter remained statistically significant.

Similar to the first set of analyses, the second set of analyses, excluding subjects with increased cocaine use between both sessions, showed no significant changes in metabolite concentrations and ratios. Similar to the first analysis, it showed a significant decrease of ADC in the thalamus $(-3.9 \%, p=0.011)$ and of $\mathrm{rrCBV}$ in the thalamus $(-6.7 \%, p=0.010)$, dorsolateral frontal cortex $(-4.2 \%$, $p=0.002)$, and superior parietal gray matter $(-3.4 \%$, $p=0.026)$. However, the increase in FA in the white matter of the centrum semiovale was not significant anymore $(p=0.085)$ and the second analysis showed an additional significant decrease of $\mathrm{rrCBV}$ in the putamen 
Table 2 MRI Parameters before and after First Ecstasy Use

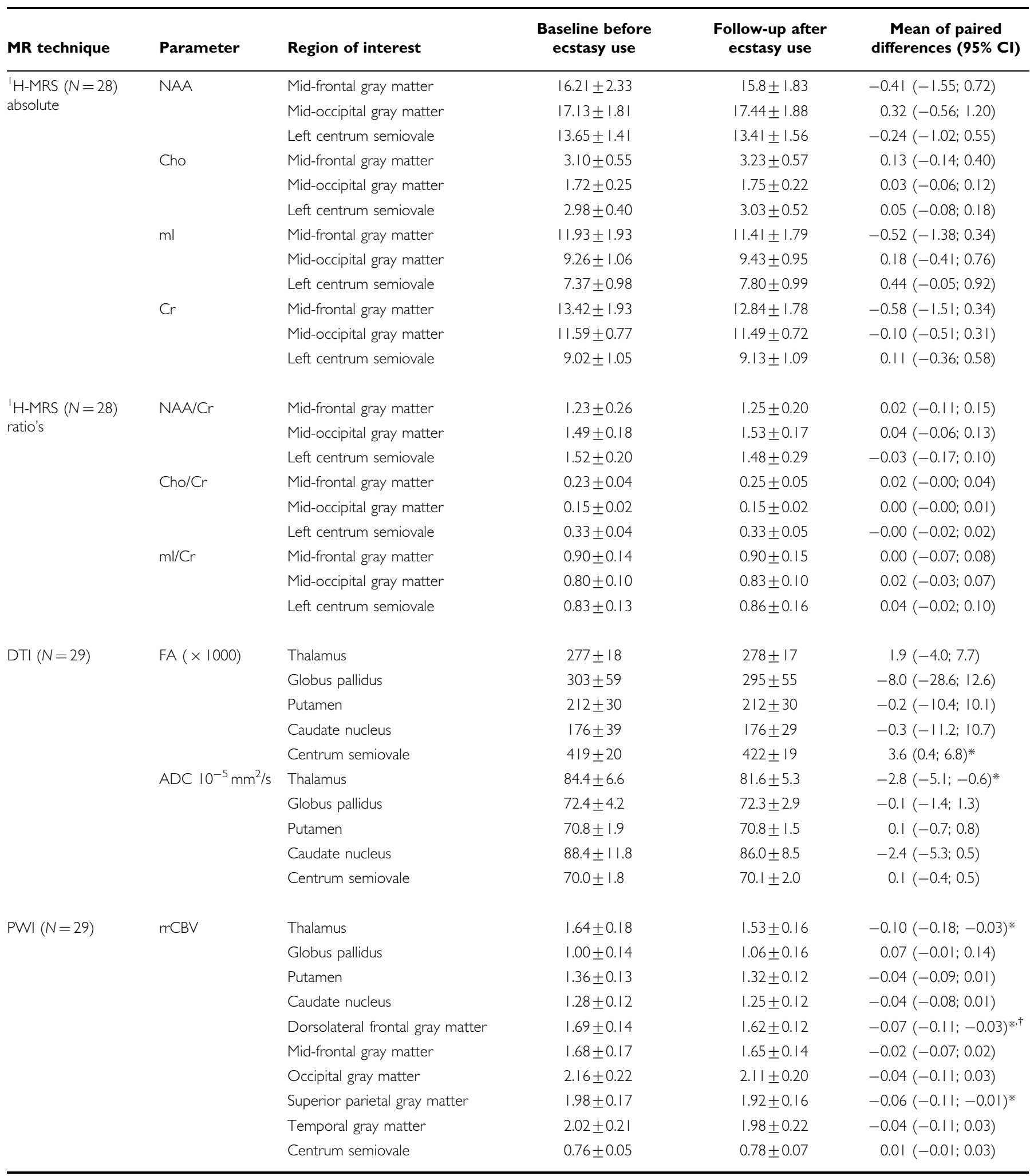

*Statistical significant difference between baseline and follow-up (paired $t$-test, uncorrected for multipele comparisons).

${ }^{\dagger}$ Statistical significant difference between baseline and follow-up (paired $t$-test, corrected for multipele comparisons).

Values expressed as mean \pm SD's. Results expressed in mean of paired differences $(95 \% \mathrm{Cl})$.

$(-3.8 \%, p=0.047)$. After correction for multiple comparisons, only the rCBV value in the dorsolateral frontal gray matter remained statistically significant.
The linear regression analyses showed a significant effect of gender on Cho/Cr in the occipital gray matter $(B=-0.02$, $p=0.038)$, on $\mathrm{Cho} / \mathrm{Cr}(B=-0.04, p=0.032)$, and on $\mathrm{rrCBV}$ 

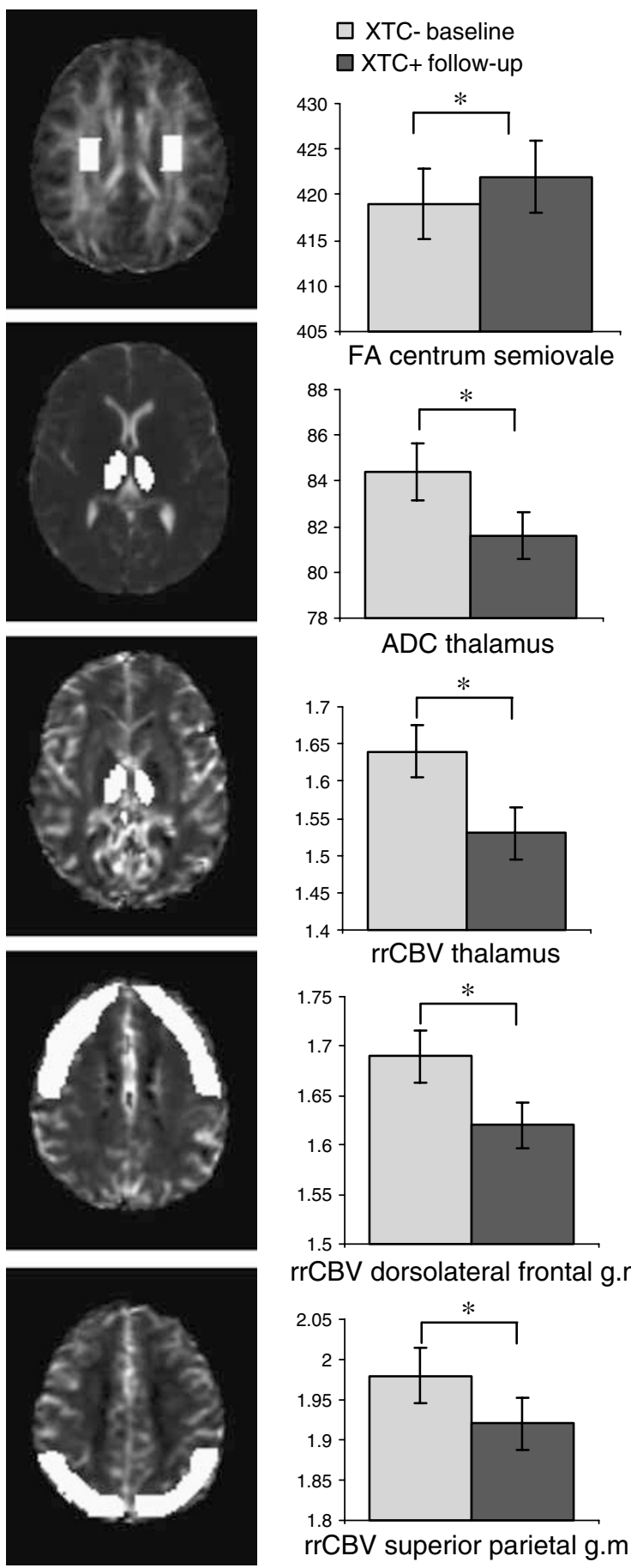

rrCBV dorsolateral frontal g.m.

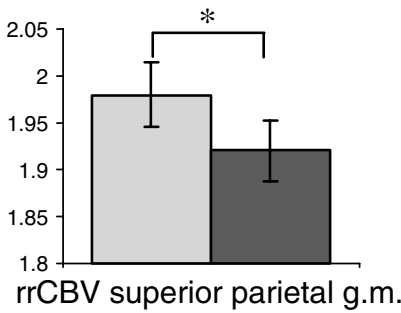

Figure 3 On the left, FA, ADC, and rCBV maps with brain regions, that significantly differed between baseline and follow-up (uncorrected for multiple comparisons), marked in white. On the right, columns reflect corresponding FA values in the centrum semiovale, ADC values in the thalamus, and rrCBV values in thalamus, dorsolateral frontal gray matter. and superior parietal gray matter at baseline before (XTC-) and at followup after ecstasy use $(X T C+)$. Results represent mean \pm SEM; $*=p<0.05$. Only significant results are shown, for complete results of all analyses see Table 2. Note that the vertical axis does not start at zero.

in the temporal gray matter $(B=-0.17, p=0.021)$. This means that females (assigned ' 2 ' in the analysis) showed a significant larger decrease in $\mathrm{Cho} / \mathrm{Cr}$ and $\mathrm{rrCBV}$ than males (assigned ' 1 ' in the analysis). The total amount of ecstasy tablets had only a significant positive effect on FA in white matter $(B=3.35, p=0.009)$ and the time since last ecstasy use had no significant effect on any of the outcome measures at the follow-up session. Increase in cocaine use was significantly related to an increase in $\mathrm{mI}$ and $\mathrm{mI} / \mathrm{Cr}$ in the occipital gray matter $(B=0.23, p=0.033$ and $B=0.02$, $p=0.019$, respectively). Of these regression analyses only the positive effect of the total amount of ecstasy tablets on $\mathrm{FA}$ in white matter remained significant after correction for multiple comparisons.

\section{Psychopathological Assessments}

Results of the self-report questionnaires on depression, impulsivity, and sensation seeking at baseline and follow-up sessions are shown in Table 1. After ecstasy use (at the follow-up session), subjects scored significantly lower on symptoms of depression $(-28.0 \%, p=0.035)$ and significantly higher on signs of impulsivity $(3.7 \%, p=0.006)$. No changes were observed in sensation seeking. Similar to the first analyses, the second analyses, excluding subjects with increased cocaine use between both sessions, showed no significant changes in sensation seeking, significant lower symptoms of depression $(-29.8 \%, p=0.045)$, and significantly higher signs of impulsivity $(3.4 \%, p=0.013)$.

The linear regression analyses showed a significant positive effect of increased cocaine use on sensation seeking $(B=0.15, p=0.026)$. There were no significant correlations between increased depression and impulsivity scores and significant changes in MR outcomes.

\section{DISCUSSION}

To our knowledge, this is the first imaging study that prospectively examined sustained effects of a low dose of ecstasy on the human brain. Given the existing data on potential neurotoxicity, it is highly controversial to give ecstasy to ecstasy-naive individuals in a controlled experiment (Gijsman et al, 1999; Lieberman and Aghajanian, 1999; Vollenweider et al, 1999; McCann and Ricaurte, 2001). Therefore, we used a naturalistic design in which young adults with a relatively high probability for first time ecstasy use were included in a follow-up study. Only a few subjects incidentally used amphetamines and cocaine, and the use of alcohol, tobacco, and cannabis before the two sessions was very similar.

${ }^{1} \mathrm{H}$-MRS and FA, parameters of structural elements of the brain, did not show indications of neuronal damage (ie, no decrease in NAA, NAA/Cr, FA, and no increase in Cho, Cho/ $\mathrm{Cr}, \mathrm{mI}, \mathrm{mI} / \mathrm{Cr}$ ) after the first use of a low dose of ecstasy. This is not unexpected, because previous observations showed that neurotoxic effects of ecstasy are probably doserelated (McCann et al, 1998; Reneman et al, 2001a; Buchert et al, 2004). Previous ${ }^{1} \mathrm{H}$-MRS studies showed decreased $\mathrm{NAA} / \mathrm{Cr}$ ratios in ecstasy users with an average cumulated dose of more than 700 tablets (Reneman et al, 2001c, 2002), while others found no decreased NAA/Cr ratios in subjects with more moderate lifetime doses (Chang et al, 1999; Daumann et al, 2004a). Therefore, these effects probably only appear after cumulative heavy use. On the other hand, 
we observed a small but significant decrease of $3.5 \%$ (Cohen's $d=-0.47$ ) in ADC in the thalamus after first ecstasy use (Cohen, 1988). We can speculate that this might be related to ecstasy-induced cytotoxic edema, as observed in other neurotoxic substances (Heaney et al, 2003; Haykin et al, 2005), although it also could be related to protracted vasoconstriction, since we also observed a decreased $\mathrm{rrCBV}$ in the thalamus (Pearson correlation between these findings is $0.65, p<0.001)$. With DTI we also encountered the unexpected finding of increased FA in the centrum semiovale related to the total amount of ecstasy tablets, although this $0.9 \%$ increase was very small (Cohen's $d=0.15$ ).

Functional parameters were measured with PWI and selfreport questionnaires. As previously observed (Reneman et al, 2001b) we found an increase in rrCBV in the globus pallidus, although this effect was not significant $(p=0.09)$. In addition, we found significant small to moderate decreases in rrCBV in dorsolateral frontal cortex, superior parietal cortex, and thalamus (Cohen's $d=0.36-0.65$ ). Decreases in cerebral blood flow (CBF), mainly in the caudate nucleus, and superior parietal and right dorsolateral frontal cortices, were previously observed after only two doses of MDMA (Chang et al, 2000). As this happened within 3 weeks after MDMA administering and because microcirculation in these areas has a strong relationship with serotonergic terminals (Cohen et al, 1996), the authors hypothesized that the decreased CBF was caused by subacute vasoconstriction due to MDMA-mediated serotonergic effects. The same study reported an increased CBF 2-3 months after MDMA intake (although only studied in two subjects) and no differences were found in CBF between controls and abstinent ecstasy users with a mean abstinence period of 6.6 months. They speculated that these findings might reflect depletion of serotonin after a longer period of abstinence and normalization of brain perfusion, respectively. Based on these results, they suggested a relationship between brain perfusion and abstinence period. Previous findings of higher rrCBVs in ecstasy users with an average period of abstinence of 14.6 weeks (globus pallidus) (Reneman et al, 2001b) and higher rrCBVs in former ecstasy users (globus pallidus and thalamus) than in recent ecstasy users and controls (Reneman et al, 2000) could be in line with this hypothesis, although study populations were small. The latter study also showed low rrCBV values in combination with lower cortical $5-\mathrm{HT}_{2}$ receptor densities, suggesting downregulation of $5-\mathrm{HT}_{2}$ receptors, in ecstasy users with a mean abstinence period of 7 weeks, and they hypothesized this was caused by excessive ecstasy-induced serotonin release. The currently observed decreased $\mathrm{rrCBV}$ values in subjects with a mean period of abstinence of 7.7 weeks might therefore also be related to a, probably transient, ecstasy-induced downregulation of $5-\mathrm{HT}_{2}$ receptors, which play an important role in the regulation of brain microcirculation (Parsons, 1991; Cohen et al, 1996). On the other hand, we did not find significant correlations between rrCBV and the time since last ecstasy tablet (abstinence interval). Another speculation is that decreased $\mathrm{rrCBV}$ values might reflect decreased brain function, because a single ecstasy dose was shown to cause degenerating neurons in parietal cortex and thalamus of rats (Schmued, 2003). In line with this, deficits in brain perfusion were reported in polydrug (Levin et al, 1996) and methamphetamine abusers (Iyo et al, 1997; Chang et al, 2002).

Outcomes of the self-report questionnaires after first ecstasy use showed increased impulsivity, as previously observed in other studies (Morgan, 1998). However, the magnitude of the effect is limited (3.7\% increase; Cohen's $d=0.34$ ) and the clinical relevance is therefore questionable. Subjects also reported lower levels of depression after ecstasy use than before, an unexpected finding that might be related to a euphoric feeling about the first ecstasy experience (Korf et al, 1991). Also here, the clinical relevance of the reduction from 4.8 to 3.4 is questionable because the effect size is rather limited (Cohen's $d=-0.38$ ) and because BDI scores between 0 and 9 are considered to be within the normal range. Moreover, it should be noted that the findings were not reproduced after a longer followup period in a larger sample of the same baseline population (De Win et al, 2006).

Although this study and some other studies showed that adverse effects of a low ecstasy dose are limited (Downing, 1986; Vollenweider et al, 1998), there are various factors (eg, poor metabolism, hypertension, young age, simultaneous use of other substances, environmental conditions) that might contribute to individual or situational vulnerability for acute adverse effects and long-term neurotoxicity of ecstasy (Buchert et al, 2001; Obrocki et al, 2002; Green et al, 2004; Segura et al, 2005). Therefore, it is not possible to state that incidental use of ecstasy is completely safe. For example, neurocognitive data from a larger sample of the current study population suggest that even low-dose ecstasy use is associated with small but significant decreases in verbal memory relative to non-users (Schilt et al, 2006).

As we used multiple techniques as indicators for ecstasyinduced brain damage and multiple regions of interests, there is an increased probability of type I errors (false positive results). Therefore, additional post hoc Bonferroni corrections on all imaging analyses were performed. The results showed that most of the significant findings did not remain significant after Bonferroni correction. On the other hand, the Bonferroni correction may be too conservative especially because a priori we expected small effects as we studied early indicators of potential brain damage in subjects with only low cumulative doses of ecstasy use. Moreover, all imaging techniques and ROIs were chosen based on a priori hypothesis. Therefore, it is likely that the Bonferroni-correction induces type II errors (false negative findings). The risk of such corrections was previously discussed by Rothman (1990) who showed that they can obscure possibly important findings (Rothman, 1990). As a result of its social impact, additional research is needed to establish whether the current uncorrected significant findings can be replicated.

A limitation of the present study is the uncertainty about variances in dosage and purity of ecstasy tablets, although pill-testing confirms that in the Netherlands more than $95 \%$ of the tablets sold as ecstasy contain MDMA as the only $(91.2 \%)$ or major $(4.2 \%)$ component (Drugs Informatie en Monitoring Systeem, 2003; The Netherlands National Drug Monitor, 2004). The MDMA-related psychoactive substances 3,4-methylenedioxy- $N$-ethylamphetamine (MDEA) or 3,4-methylenedioxyamphetamine (MDA) are major components in $1.5 \%$ of the ecstasy tablets and only $1 \%$ of 
the ecstasy tablets contain amphetamine. The mean concentration of MDMA in an ecstasy tablet was $78 \mathrm{mg}$ in 2003 in the Netherlands, but there is an increase in tablets with a dose of more than $140 \mathrm{mg}$ MDMA (The Netherlands National Drug Monitor, 2004). Also the environmental circumstances under which ecstasy was taken and the simultaneous use of other substances was heterogeneous. As a result of these changing circumstances, it is possible that the observed changes in FA, ADC, rrCBV, depression, and impulsivity are not related to ecstasy use, but to other timeor ecstasy-related variables. Confounding by the use of other substances, such as alcohol, nicotine, cannabis, amphetamines, and cocaine, cannot be totally excluded, although alcohol, nicotine, cannabis, and amphetamine use did not change between sessions and most effects remained significant after exclusion of subjects with increased use of cocaine between sessions.

Another limitation is that we did not include a control group. Therefore, we cannot be completely sure about the reproducibility of our measurements. Other studies suggest that reproducibility of ${ }^{1} \mathrm{H}-\mathrm{MRS}$ (Schirmer and Auer, 2000), DTI (Brockstedt et al, 1999; Cassol et al, 2004) and PWI (Henry et al, 2001) is good, although this might depend on the scanner, the scan protocol, and post-processing procedures. ROIs were drawn in the spatially normalized MNI brain template, which may have introduced additional variance due to inherent variations in mapping of individual brains to the MNI brain. On the other hand, compared to drawing ROIs for each individual subject, the current procedure is user-independent and reproducible, because the same procedure is performed for all subjects exactly in the same way. As few studies used ${ }^{1} \mathrm{H}-\mathrm{MRS}$, DTI, and PWI to study neuronal damage in ecstasy users, little is known about the sensitivity and specificity of these techniques to detect ecstasy-induced neuronal damage. Therefore, additional studies are needed, both in animals and in heavy human ecstasy users. As expected neuronal damage after a low dose of ecstasy is relatively small, the statistical power of this study could have been insufficient for ${ }^{1} \mathrm{H}-\mathrm{MRS}$ and DTI to detect changes. DTI is particularly suitable for detection of white matter lesions, while ecstasyrelated neuronal damage is especially expected in basal ganglia and cerebral cortex. As these areas have low FA, the sensitivity of this parameter to detect axonal dysfunction in basal ganglia might be limited. On the other hand, ${ }^{1} \mathrm{H}-\mathrm{MRS}$, DTI, and PWI have been shown to be sensitive tools in various neuropsychiatric disorders. For example, ${ }^{1} \mathrm{H}-\mathrm{MRS}$ showed to be sensitive to detect changes in patients with schizophrenia, affective disorders, autism, and depression (Stanley, 2002; Kumar et al, 2002) and substance users (Ernst et al, 2000; Nordahl et al, 2002; Reneman et al, 2006). DTI showed to be sensitive in detection of early diffuse axonal injury after traumatic brain injury (Arfanakis et al, 2002) and various neuropsychiatric disorders (Lim and Helpern, 2002). PWI showed to be sensitive in detection of rrCBV deficits in early Alzheimer's disease (Harris et al, 1998; Bozzao et al, 2001) and in other neuropsychiatric diseases (Renshaw et al, 1997).

In conclusion, with the currently used techniques we found no indications for structural neuronal damage after a low dose of ecstasy use in first time ecstasy users. Therefore, these data do not support the concern that incidental ecstasy use leads to serious axonal loss, although more studies are needed to assess the sensitivity of the currently used MR techniques to detect small ecstasy-induced neuronal changes. However, our findings of decreased rrCBV and ADC may indicate that even a low dose of ecstasy can induce sustained vasoconstriction in some brain areas, although we do not know whether these findings are permanent. Therefore, and because there may be various personal and environmental factors that play a role in the occurrence of acute and long-term effects of ecstasy, it is impossible to state, based on this study, that incidental use of ecstasy is totally safe for the brain.

\section{ACKNOWLEDGEMENTS}

The NeXT study was supported by a grant of The Netherlands Organization for Health Research and Development as part of their Addiction Program (ZonMw 310-00036). Sílvia D Olabarriaga participates in the Virtual Laboratory for e-Science project, which is supported by a BSIK grant from the Dutch Ministry of Education, Culture and Science (OC\&W) and is part of the ICT innovation program of the Ministry of Economic Affairs (EZ). Questionnaires on drug use were obtained by courtesy of the Addiction Research Institute of the University of Utrecht. We thank Professor M Moseley (Lucas MRS Center, Stanford University) for support in the implementation of the DTI protocol. We thank Hylke Vervaeke for recruiting volunteers; Sarah Dijkink for assistance with data collection and Jeroen Snel for assistance with postprocessing of DTI and PWI scans.

\section{REFERENCES}

Arfanakis K, Haughton VM, Carew JD, Rogers BP, Dempsey RJ, Meyerand ME (2002). Diffusion tensor MR imaging in diffuse axonal injury. AJNR Am J Neuroradiol 23: 794-802.

Beck AT, Ward CH, Mendelson M, Mock J, Erbaugh J (1961). An inventory for measuring depression. Arch Gen Psychiatry 4: 561-571.

Belliveau JW, Rosen BR, Kantor HL, Rzedzian RR, Kennedy DN, McKinstry RC et al (1990). Functional cerebral imaging by susceptibility-contrast NMR. Magn Reson Med 14: 538-546.

Bender E (2005). FDA approves study of ecstasy in some terminally ill patients. Psychiatric News 40: 46.

Bodammer N, Kaufmann J, Kanowski M, Tempelmann C (2004). Eddy current correction in diffusion-weighted imaging using pairs of images acquired with opposite diffusion gradient polarity. Magn Reson Med 51: 188-193.

Bond AJ, Verheyden SL, Wingrove J, Curran HV (2004). Angry cognitive bias, trait aggression and impulsivity in substance users. Psychopharmacology 171: 331-339.

Bozzao A, Floris R, Baviera ME, Apruzzese A, Simonetti G (2001). Diffusion and perfusion MR imaging in cases of Alzheimer's disease: correlations with cortical atrophy and lesion load. AJNR Am J Neuroradiol 22: 1030-1036.

Brockstedt S, Borg M, Geijer B, Wirestam R, Thomsen C, Holtas S et al (1999). Triggering in quantitative diffusion imaging with single-shot EPI. Acta Radiol 40: 263-269.

Buchert R, Obrocki J, Thomasius R, Vaterlein O, Petersen K, Jenicke L et al (2001). Long-term effects of 'ecstasy' abuse on the human brain studied by FDG PET. Nucl Med Commun 22: 889-897. 
Buchert R, Thomasius R, Wilke F, Petersen K, Nebeling B, Obrocki $\mathrm{J}$ et al (2004). A voxel-based PET investigation of the long-term effects of 'ecstasy' consumption on brain serotonin transporters. Am J Psychiatry 161: 1181-1189.

Butler GK, Montgomery AM (2004). Impulsivity, risk taking and recreational 'ecstasy' (MDMA) use. Drug Alcohol Depend 76: 55-62.

Camí J, Farré M, Mas M, Roset PN, Poudevida S, Mas A et al (2000). Human pharmacology of 3,4-methylenedioxymethamphetamine ('ecstasy'): psychomotor performance and subjective effects. J Clin Psychopharmacol 20: 455-466.

Cassol E, Ranjeva JP, Ibarrola D, Mekies C, Manelfe C, Clanet M et al (2004). Diffusion tensor imaging in multiple sclerosis: a tool for monitoring changes in normal-appearing white matter. Mult Scler 10: 188-196.

Chang L, Ernst T, Grob CS, Poland RE (1999). Cerebral ${ }^{1} \mathrm{H}$ MRS alterations in recreational 3, 4-methylenedioxymethamphetamine (MDMA, 'ecstasy') users. J Magn Reson Imaging 10: 521-526.

Chang L, Ernst T, Speck O, Patel H, DeSilva M, Leonido-Yee M et al (2002). Perfusion MRI and computerized cognitive test abnormalities in abstinent methamphetamine users. Psychiatry Res 114: 65-79.

Chang L, Grob CS, Ernst T, Itti L, Mishkin FS, Jose-Melchor R et al (2000). Effect of ecstasy [3,4-methylenedioxymethamphetamine (MDMA)] on cerebral blood flow: a co-registered SPECT and MRI study. Psychiatry Res 98: 15-28.

Check E (2004). Psychedelic drugs: the ups and downs of ecstasy. Nature 429: 126-128.

Chen CY, Lee KW, Lee CC, Chin SC, Chung HW, Zimmerman RA (2000). Heroin-induced spongiform leukoencephalopathy: value of diffusion MR imaging. J Comput Assist Tomogr 24: 735-737.

Chu K, Jung KH, Kim HJ, Jeong SW, Kang DW, Roh JK (2004). Diffusion-weighted MRI and ${ }^{99 \mathrm{~m}} \mathrm{Tc}-\mathrm{HMPAO}$ SPECT in delayed relapsing type of carbon monoxide poisoning: evidence of delayed cytotoxic edema. Eur Neurol 51: 98-103.

Cohen J (1988). Statistical Power Analysis for the Behavioral Sciences. Lawrence Earlbaum Associates: Hillsdale, NJ.

Cohen Z, Bonvento G, Lacombe P, Hamel E (1996). Serotonin in the regulation of brain microcirculation. Prog Neurobiol 50: 335-362.

Colado MI, Williams JL, Green AR (1995). The hyperthermic and neurotoxic effects of 'ecstasy' (MDMA) and 3,4 methylenedioxyamphetamine (MDA) in the dark agouti (DA) rat, a model of the CYP2D6 poor metabolizer phenotype. Br J Pharmacol 115: $1281-1289$.

Copen WA, Schwamm LH, Gonzalez RG, Wu O, Harmath CB, Schaefer PW et al (2001). Ischemic stroke: effects of etiology and patient age on the time course of the core apparent diffusion coefficient. Radiology 221: 27-34.

Daumann J, Fischermann T, Pilatus U, Thron A, MoellerHartmann W, Gouzoulis-Mayfrank E (2004a). Proton magnetic resonance spectroscopy in ecstasy (MDMA) users. Neurosci Lett 362: 113-116.

Daumann J, Hensen G, Thimm B, Rezk M, Till B, GouzoulisMayfrank E (2004b). Self-reported psychopathological symptoms in recreational ecstasy (MDMA) users are mainly associated with regular cannabis use: further evidence from a combined cross-sectional/longitudinal investigation. Psychopharmacology 173: 398-404.

Daumann J, Pelz S, Becker S, Tuchtenhagen F, GouzoulisMayfrank E (2001). Psychological profile of abstinent recreational Ecstasy (MDMA) users and significance of concomitant cannabis use. Human Psychopharmacology-Clinical and Experimental 16: 627-633.

De Win MML, Jager G, Vervaeke H, Schilt T, Reneman L, Booij J et al (2005). The Netherlands XTC Toxicity (NeXT) study: objectives and methods of a study investigating causality, course, and clinical relevance. Int J Methods in Psychiatric Research 14: 167-185.

De Win MML, Schilt T, Reneman L, Vervaeke H, Jager G, Dijkink S et al (2006). Ecstasy use and self-reported depression, impulsivity, and sensation seeking: a prospective cohort study. J Psychopharmacol 20: 226-235.

Downing J (1986). The psychological and physiological effects of MDMA on normal volunteers. J Psychoactive Drugs 18: 335-340.

Drugs Informatie en Monitoring Systeem (2003). Rapportage gegevens 2002. DIMS/Trimbos-instituut: Utrecht.

Dughiero G, Schifano F, Forza G (2001). Personality dimensions and psychopathological profiles of ecstasy users. Hum Psychopharmacol 16: 635-639.

Ernst T, Chang L, Leonido-Yee M, Speck O (2000). Evidence for long-term neurotoxicity associated with methamphetamine abuse: a ${ }^{1}$ H MRS study. Neurology 54: 1344-1349.

Feij JA, van Zuilen RW (1984). Handleiding bij de spanningsbehoeftelijst (SBL). Swets \& Zeitlinger: Lisse.

Feij JA, van Zuilen RW, Gazendam A (1982). De ontwikkeling van een Nederlandse vragenlijst voor sensation seeking: de spanningsbehoeftelijst (SBL). Gedrag 10: 364-383.

Gamma A, Buck A, Berthold T, Liechti ME, Vollenweider FX (2000). 3,4-Methylenedioxymethamphetamine (MDMA) modulates cortical and limbic brain activity as measured by $\left[\mathrm{H} 2{ }^{15} \mathrm{O}\right]-$ PET in healthy humans. Neuropsychopharmacology 23: 388-395.

Gerra G, Zaimovic A, Giucastro G, Maestri D, Monica C, Sartori R et al (1998). Serotonergic function after ( \pm )3,4-methylenedioxymethamphetamine ('ecstasy') in humans. Int Clin Psychopharmacol 13: 1-9.

Gijsman HJ, Verkes RJ, van Gerven JM, Cohen AF (1999). MDMA study. Neuropsychopharmacology 21: 597.

Green AR, O'shea E, Colado MI (2004). A review of the mechanisms involved in the acute MDMA (ecstasy)-induced hyperthermic response. Eur J Pharmacol 500: 3-13.

Greer G, Tolbert R (1986). Subjective reports of the effects of MDMA in a clinical setting. J Psychoactive Drugs 18: 319-327.

Grob CS (2002). The politics of ecstasy. J Psychoactive Drugs 34: 143-144.

Grob CS, Poland RE, Chang L, Ernst T (1996). Psychobiologic effects of 3,4-methylenedioxymethamphetamine in humans: methodological considerations and preliminary observations. Behav Brain Res 73: 103-107.

Gudbjartsson H, Patz S (1995). The Rician distribution of noisy MRI data. Magn Reson Med 34: 910-914.

Hanyu S, Ikeguchi K, Imai H, Imai N, Yoshida M (1995). Cerebral infarction associated with 3,4-methylenedioxymethamphetamine ('ecstasy') abuse. Eur Neurol 35: 173.

Harris GJ, Lewis RF, Satlin A, English CD, Scott TM, YurgelunTodd DA et al (1998). Dynamic susceptibility contrast MR imaging of regional cerebral blood volume in Alzheimer disease: a promising alternative to nuclear medicine. AJNR Am J Neuroradiol 19: 1727-1732.

Haykin ME, Gorman M, van Hof J, Fulbright RK, aehring JM (2005). Diffusion-weighted MRI correlates of subacute methotrexate-related neurotoxicity. J Neurooncol.

Heaney CJ, Campeau NG, Lindell EP (2003). MR imaging and diffusion-weighted imaging changes in metronidazole (Flagyl)-induced cerebellar toxicity. AJNR Am J Neuroradiol 24: 1615-1617.

Henry ME, Kaufman MJ, Lange N, Schmidt ME, Purcell S, Cote J et al (2001). Test-retest reliability of DSC MRI CBV mapping in healthy volunteers. Neuroreport 12: 1567-1569.

Ho YJ, Pawlak CR, Guo L, Schwarting RK (2004). Acute and longterm consequences of single MDMA administration in relation to individual anxiety levels in the rat. Behav Brain Res 149: 135-144. 
Hunsche S, Moseley ME, Stoeter P, Hedehus M (2001). Diffusiontensor MR imaging at 1.5 and $3.0 \mathrm{~T}$ : initial observations. Radiology 221: 550-556.

Iyo M, Namba H, Yanagisawa M, Hirai S, Yui N, Fukui S (1997). Abnormal cerebral perfusion in chronic methamphetamine abusers: a study using 99MTc-HMPAO and SPECT. Prog Neuropsychopharmacol Biol Psychiatry 21: 789-796.

Jansen KL, Forrest AR (1999). Toxic effect of MDMA on brain serotonin neurons. Lancet 353: 1270-1271.

Khantzian EJ (1997). The self-medication hypothesis of substance use disorders: a reconsideration and recent applications. Harv Rev Psychiatry 4: 231-244.

Kish SJ (2002). How strong is the evidence that brain serotonin neurons are damaged in human users of ecstasy? Pharmacol Biochem Behav 71: 845-855.

Korf DJ, Blanken P, Nabben T (1991). Een nieuwe wonderpil? Verspreiding, effecten en risico's van ecstasygebruik in Amsterdam. Jellinekcentrum/IADA: Amsterdam.

Kumar A, Thomas A, Lavretsky H, Yue K, Huda A, Curran J et al (2002). Frontal white matter biochemical abnormalities in latelife major depression detected with proton magnetic resonance spectroscopy. Am J Psychiatry 159: 630-636.

Lee GYF, Gong GWK, Vrodos N, Brophy PB (2003). 'Ecstasy'induced subarachnoid haemorrhage: an under-reported neurological complication? J Clin Neurosci 10: 705-707.

Levin JM, Ross MH, Harris G, Renshaw PF (1996). Applications of dynamic susceptibility contrast magnetic resonance imaging in Neuropsychiatry. Neuroimage 4: S147-S162.

Lieberman JA, Aghajanian GK (1999). Caveat emptor: researcher beware. Neuropsychopharmacology 21: 471-473.

Liechti ME, Baumann C, Gamma A, Vollenweider FX (2000). Acute psychological effects of 3,4-methylenedioxymethamphetamine (MDMA, 'ecstasy') are attenuated by the serotonin uptake inhibitor citalopram. Neuropsychopharmacology 22: 513-521.

Liechti ME, Vollenweider FX (2000a). Acute psychological and physiological effects of MDMA ('ecstasy') after haloperidol pretreatment in healthy humans. Eur Neuropsychopharmacol 10: 289-295.

Liechti ME, Vollenweider FX (2000b). The serotonin uptake inhibitor citalopram reduces acute cardiovascular and vegetative effects of 3,4-methylenedioxymethamphetamine ('ecstasy') in healthy volunteers. J Psychopharmacol 14: 269-274.

Lim KO, Helpern JA (2002). Neuropsychiatric applications of DTI - a review. NMR Biomed 15: 587-593.

McCann UD, Eligulashvili V, Ricaurte GA (2000). 3,4-Methylenedioxymethamphetamine ('ecstasy')-induced serotonin neurotoxicity: clinical studies. Neuropsychobiology 42: 11-16.

McCann UD, Ricaurte GA (2001). Caveat emptor: editors beware. Neuropsychopharmacology 24: 333-336.

McCann UD, Szabo Z, Scheffel U, Dannals RF, Ricaurte GA (1998). Positron emission tomographic evidence of toxic effect of MDMA ('ecstasy') on brain serotonin neurons in human beings. Lancet 352: 1433-1437.

McGuire PK, Cope H, Fahy TA (1994). Diversity of psychopathology associated with use of 3,4-methylenedioxymethamphetamine ('ecstasy'). Br J Psychiatry 165: 391-395.

Mechan A, Yuan J, Hatzidimitriou G, Irvine RJ, McCann UD, Ricaurte GA (2006). Pharmacokinetic profile of single and repeated oral doses of MDMA in squirrel monkeys: relationship to lasting effects on brain serotonin neurons. Neuropsychopharmacology 31: 339-350.

Miller BL, Chang L, Booth R, Ernst T, Cornford M, Nikas D et al (1996). In vivo ${ }^{1} \mathrm{H}$ MRS choline: correlation with in vitro chemistry/histology. Life Sci 58: 1929-1935.

Morgan JF (1999). Toxic effect of MDMA on brain serotonin neurons. Lancet 353: 1268-1269.
Morgan MJ (1998). Recreational use of 'ecstasy' (MDMA) is associated with elevated impulsivity. Neuropsychopharmacology 19: 252-264.

Morgan MJ (2000). Ecstasy (MDMA): a review of its possible persistent psychological effects. Psychopharmacology (Berlin) 152: $230-248$.

Murata T, Kimura H, Kado H, Omori M, Onizuka J, Takahashi T et al (2001). Neuronal damage in the interval form of $\mathrm{CO}$ poisoning determined by serial diffusion weighted magnetic resonance imaging plus ${ }^{1} \mathrm{H}$-magnetic resonance spectroscopy. J Neurol Neurosurg Psychiatry 71: 250-253.

Nelson HE (1991). The Revised National Adult Reading Test Manual. NFER-Nelson: Windsor.

Nordahl TE, Salo R, Possin K, Gibson DR, Flynn N, Leamon M et al (2002). Low $N$-acetyl-aspartate and high choline in the anterior cingulum of recently abstinent methamphetamine-dependent subjects: a preliminary proton MRS study. Magnetic resonance spectroscopy. Psychiatry Res 116: 43-52.

Obrocki J, Schmoldt A, Buchert R, Andresen B, Petersen K, Thomasius R (2002). Specific neurotoxicity of chronic use of ecstasy. Toxicol Lett 127: 285-297.

Parrott AC, Sisk E, Turner JJD (2000). Psychobiological problems in heavy 'ecstasy' (MDMA) polydrug users. Drug and Alcohol Dependence 60: 105-110.

Parsons AA (1991). 5-HT receptors in human and animal cerebrovasculature. Trends Pharmacol Sci 12: 310-315.

Patton JH, Stanford MS, Barratt ES (1995). Factor structure of the Barratt Impulsiveness Scale. Journal of Clinical Psychology 51: 768-774.

Pouwels PJ, Frahm J (1998). Regional metabolite concentrations in human brain as determined by quantitative localized proton MRS. Magn Reson Med 39: 53-60.

Provencher SW (1993). Estimation of metabolite concentrations from localized in vivo proton NMR spectra. Magn Reson Med 30: 672-679.

Reneman L, Booij J, de Bruin K, Reitsma JB, de Wolff FA, Gunning WB et al (2001a). Effects of dose, sex, and long-term abstention from use on toxic effects of MDMA (ecstasy) on brain serotonin neurons. Lancet 358: 1864-1869.

Reneman L, de Win MM, van den Brink W, Booij J, den Heeten GJ (2006). Neuroimaging findings with MDMA/ecstasy: technical aspects, conceptual issues and future prospects. J Psychopharmacol 20: 164-175.

Reneman L, Habraken JB, Majoie CB, Booij J, den Heeten GJ (2000). MDMA ('ecstasy') and its association with cerebrovascular accidents: preliminary findings. AJNR Am J Neuroradiol 21: 1001-1007.

Reneman L, Majoie CB, Flick H, den Heeten GJ (2002). Reduced Nacetylaspartate levels in the frontal cortex of 3,4-methylenedioxymethamphetamine (ecstasy) users: preliminary results. AJNR Am J Neuroradiol 23: 231-237.

Reneman L, Majoie CB, Habraken JB, den Heeten GJ (2001b). Effects of ecstasy (MDMA) on the brain in abstinent users: initial observations with diffusion and perfusion MR imaging. Radiology 220: 611-617.

Reneman L, Majoie CB, Schmand B, van den Brink W, den Heeten GJ (2001c). Prefrontal $N$-acetylaspartate is strongly associated with memory performance in (abstinent) ecstasy users: preliminary report. Biol Psychiatry 50: 550-554.

Renshaw PF, Levin JM, Kaufman MJ, Ross MH, Lewis RF, Harris GJ (1997). Dynamic susceptibility contrast magnetic resonance imaging in neuropsychiatry: present utility and future promise. Eur Radiol 7(Suppl 5): 216-221.

Ricaurte GA, DeLanney LE, Irwin I, Langston JW (1988). Toxic effects of MDMA on central serotonergic neurons in the primate: importance of route and frequency of drug administration. Brain Res 446: 165-168. 
Ricaurte GA, Yuan J, McCann UD (2000). 3,4-Methylenedioxymethamphetamine ('ecstasy')-induced serotonin neurotoxicity: studies in animals. Neuropsychobiology 42: 5-10.

Ross BD, Bluml S, Cowan R, Danielsen E, Farrow N, Gruetter R (1997). In vivo magnetic resonance spectroscopy of human brain: the biophysical basis of dementia. Biophys Chem 68: 161-172.

Rothman KJ (1990). No adjustments are needed for multiple comparisons. Epidemiology 1: 43-46.

Schifano F (2000). Potential human neurotoxicity of MDMA ('ecstasy'): subjective self-reports, evidence from an Italian Drug Addiction Centre and clinical case studies. Neuropsychobiology 42: $25-33$.

Schilt T, de Win MML, Koeter M, Jager G, Korf DJ, van den Brink $\mathrm{W}$ et al (2006). Cognition in novice ecstasy users with minimal exposure to other drugs: a prospective cohort study. Arch Gen Psych (in press).

Schirmer T, Auer DP (2000). On the reliability of quantitative clinical magnetic resonance spectroscopy of the human brain. NMR Biomed 13: 28-36.

Schmued LC (2003). Demonstration and localization of neuronal degeneration in the rat forebrain following a single exposure to MDMA. Brain Res 974: 127-133.

Segura M, Farre M, Pichini S, Peiro AM, Roset PN, Ramirez A et al (2005). Contribution of cytochrome P450 2D6 to 3,4-methylenedioxymethamphetamine disposition in humans: use of paroxetine as a metabolic inhibitor probe. Clin Pharmacokinet 44: $649-660$.

Smith SM (2002). Fast robust automated brain extraction. Hum Brain Mapp 17: 143-155.

Smith SM, Jenkinson M, Woolrich MW, Beckmann CF, Behrens TE, Johansen-Berg $\mathrm{H}$ et al (2004). Advances in functional and structural MR image analysis and implementation as FSL. Neuroimage 23(Suppl 1): S208-S219.

Srinivasan R, Vigneron D, Sailasuta N, Hurd R, Nelson S (2004). A comparative study of myo-inositol quantification using LCmodel at $1.5 \mathrm{~T}$ and $3.0 \mathrm{~T}$ with $3 \mathrm{D}^{1} \mathrm{H}$ proton spectroscopic imaging of the human brain. Magn Reson Imaging 22: 523-528.

Stanley JA (2002). In vivo magnetic resonance spectroscopy and its application to neuropsychiatric disorders. Can J Psychiatry 47: 315-326.
Sumnall HR, Cole JC (2005). Self-reported depressive symptomatology in community samples of polysubstance misusers who report ecstasy use: a meta-analysis. J Psychopharmacol 19: 84-92.

The Netherlands National Drug Monitor (2004). Annual Report 2004. Trimbos Institute: Utrecht.

Tuchtenhagen F, Daumann J, Norra C, Gobbelé R, Becker S, Pelz S et al (2000). High intensity dependence of auditory evoked dipole source activity indicates decreased serotonergic activity in abstinent ecstasy (MDMA) users. Neuropsychopharmacology 22: 608-617.

Turner JJ, Parrott AC (2000). Is MDMA a human neurotoxin? Diverse views from the discussants. Neuropsychobiology 42: 42-48.

Vaiva G, Boss V, Bailly D, Thomas P, Lestavel P, Goudemand M (2001). An 'accidental' acute psychosis with ecstasy use. J Psychoactive Drugs 33: 95-98.

Van de Wijngaart G, Braam R, de Bruin D, Fris M, Maalsté N, Verbraeck H (1997). Ecstasy in het uitgaanscircuit (ecstasy and the Dutch rave scene: A socio-epidemiologic study on the nature and extent of, and the risks involved in using ecstasy and other party drugs at dance events). Addiction Research Institute: Utrecht.

Vollenweider FX, Gamma A, Liechti M, Huber T (1998). Psychological and cardiovascular effects and short-term sequelae of MDMA ('ecstasy') in MDMA-naïve healthy volunteers. Neuropsychopharmacology 19: 241-251.

Vollenweider FX, Gamma A, Liechti M, Huber T (1999). Is a single dose of MDMA harmless? Neuropsychopharmacology 21: 598-600.

Vollenweider FX, Jones RT, Baggott MJ (2001). Caveat emptor: editors beware. Neuropsychopharmacology 24: 461-463.

Woods RP, Grafton ST, Holmes CJ, Cherry SR, Mazziotta JC (1998). Automated image registration: I. General methods and intrasubject, intramodality validation. J Comput Assist Tomogr 22: 139-152.

Zuckerman M, Kuhlman DM (2000). Personality and risk-taking: common biosocial factors. J Pers 68: 999-1029.

Zuckerman M, Link K (1968). Construct validity for the sensationseeking scale. J Consult Clin Psychol 32: 420-426. 